\title{
Androgen Replacement Therapy in Late-Onset Hypogonadism: Current Concepts and Controversies - A Mini-Review
}

\author{
Juuso I. Mäkinen ${ }^{\mathrm{a}, \mathrm{c}}$ Ilpo Huhtaniemi ${ }^{\mathrm{b}, \mathrm{d}}$ \\ ${ }^{a}$ Department of Internal Medicine, Satakunta Central Hospital, Pori, ${ }^{b}$ Department of Physiology and \\ ${ }^{c}$ Research Centre for Applied and Preventive Cardiovascular Medicine, University of Turku, Turku, Finland; \\ ${ }^{\mathrm{d}}$ Department of Surgery and Cancer, Hammersmith Campus, Imperial College London, London, UK
}

\section{Key Words}

Ageing men · Testosterone $\cdot$ Late-onset hypogonadism •

Testosterone replacement therapy

\begin{abstract}
Background: Normal testicular function is essential for the maintenance of male physical strength and behaviour irrespective of age. A new term of late-onset hypogonadism $(\mathrm{LOH})$ has been coined for the condition of decreased testosterone $(\mathrm{T})$ and hypogonadal symptoms in ageing men. $\mathbf{O b}$ jective: The most important testicular hormone, $\mathrm{T}$, is responsible for the gender-specific androgenic-anabolic effects in men. Testicular T production remains stable until around the age of 40 years after which it declines by $1-2 \%$ annually. Despite this age-related decline, serum T levels in most older men remain within the reference range of younger men. The decreasing androgen levels are paralleled by well-defined objective biological and nonspecific subjective signs and symptoms of ageing. Because these symptoms are similar to those observed in young men with documented hypogonadism, androgen replacement therapy (ART) has been considered a logical way to treat them. Methods: A thorough review of the existing literature was performed to evaluate the current concepts and controversies related to ageing
\end{abstract}

men and ART. Results: Although it is intuitively logical that the symptoms of $\mathrm{LOH}$ are due to the ageing-related deficiency of T, and that they can be reversed by ART, the evidence for this is still variable and often weak. In particular, evidence-based information about long-term benefits and risks of ART in ageing men is largely missing. Conclusions: Despite widespread use, evidence-based proof for the objective benefits and side effects of ART of elderly men is still scanty, and such treatments should be considered experimental.

Copyright $\odot 2010$ S. Karger AG, Basel

\section{Introduction}

Since the early 1900s, the number of individuals over 65 years of age has increased more than 10 -fold, and according to the current demographic trends, the size of the population over 65 years of age will continue to increase. The concomitant developments in medicine offer more

Only key references are cited in the text. The complete list of references is available on request from the authors, E-Mail: juumak@ utu.fi or ilpo.huhtaniemi@imperial.ac.uk.

\section{KARGER}

Fax +4161306 1234

E-Mail karger@karger.ch

www.karger.com
(C) 2010 S. Karger AG, Basel

0304-324X/11/0573-0193\$38.00/0

Accessible online at:

www.karger.com/ger
Juuso Mäkinen, $\mathrm{MD}, \mathrm{PhD}$

Research Centre for Applied and Preventive Cardiovascular Medicine

Turku University Hospital, Kiinamyllynkatu 4-8

FIN-20500 Turku (Finland)

Tel. +358231300 00, Fax +358223588 11, E-Mail juumak@utu.fi 
advanced treatments to promote healthy ageing. While the quality of life of ageing women following the abrupt menopausal cessation of ovarian hormone production can be maintained by hormone replacement therapy, in men the ageing-related decline in hormone levels and the associated symptoms are more complex. The decline in testicular endocrine function (that is T production) is diffuse compared to women, and the decline starts slowly and with great individual variability around the age of 40 years. Moreover, the majority of men remain eugonadal even in advanced age. Due to this clear difference compared with women's menopause the recommended term for the hormonal decline in ageing men is late-onset hypogonadism (LOH) [1].

The importance of the testes for the maintenance of male physical strength and behavior has been recognized for centuries. In the 19th century, the French physiologist Charles-Édouard Brown-Séquard treated himself with testicular extracts of guinea pigs and dogs aiming to reverse ageing symptoms, though without objective success. More recently in the 1920 s to 1930 s, a Russian surgeon, Serge Voronoff, gained fame in France by subcutaneously grafting monkey testicle tissue on men for purported rejuvenation effects, but these experiments also failed to produce objective results. The term 'male climacterium' was coined in 1939 by A.A. Werner describing ageing-associated decrement of androgens and their associated symptoms [2]. Since then, the concept of ageing-related decline of testicular function has been waxing and waning until a renaissance in the early 1990s, and today androgen replacement therapy (ART) of ageing men is again fashionable.

\section{Changes in Testosterone Production with Age}

After early adulthood all physiological functions gradually decline. The clearest physiological changes with ageing include increase in fat mass, decreased immune function and bone mineral density, and loss of muscle mass and strength. These changes are suggested to be associated with declining hormone levels. Clinically significant declines of thyroid and pancreatic functions occur with ageing, leading subtly to primary hypothyroidism and impaired glucose tolerance [3]. Similar declines have been observed in hormone production of the adrenal glands (in particular androgens) and testes, and in the production of growth hormone, adrenocorticotrophic hormone, melatonin and insulin-like growth factor (IGF)-1 [3]. The testosterone ( $\mathrm{T}$ ) concentration in men remains stable until around the age of 40 years, after which the circulating level of total $\mathrm{T}$ decreases by $1-2 \%$ annually and that of the biologically active free $\mathrm{T}$ by $2-3 \%$ $[4,5]$. The reduction in the concentration of total $\mathrm{T}$ appears to stabilize around the age of 70 years. In ageing men the diurnal rhythmicity of T secretion is dampened, and the response of $\mathrm{T}$ to luteinising hormone and human chorionic gonadotropin is generally reduced. This, together with changes in the proximal part of the hypothalamic-pituitary-testicular function, results in decreased $\mathrm{T}$ production. Chronic illnesses, hypertension, coronary artery disease, obesity and diabetes mellitus are associated with reduced $\mathrm{T}$ concentrations in middle-aged men, but also many acute severe illnesses seem to produce hypogonadotropic hypogonadism [6]. The hormonal equilibrium is fragile, since also lifestyle and psychosocial factors influence the secretion of T [6]. Hypogonadism, as defined by serum $\mathrm{T}$ levels below the reference range of adult men, is common in old men: in a study of 890 men over 80 years of age, $49 \%$ had a total T concentration and 91\% had the free $\mathrm{T}$ concentration below the reference range [7]. Recent findings of the European Male Ageing Study $[4,8]$ demonstrate that the purely ageing-related decline in testicular function is primary (with compensated increase in gonadotropins), whereas it is secondary (no compensated gonadotropin rise) if it is mainly caused by obesity or co-morbidities.

\section{The Definition of LOH and Diagnostic Criteria for Hormone Replacement Therapy}

The recommended indications for $\mathrm{T}$ replacement therapy in $\mathrm{LOH}$ include low $\mathrm{T}$ levels together with typical symptoms [1]. These include reduced muscle mass and muscle strength, increased fat mass, decreased bone mineral density, decreased morning erections, decreased libido and sexual activity, increased erectile dysfunction, sweating, insomnia, depression and nervousness [1]. However, we still do not know exactly which ones of these diffuse symptoms ascribed to $\mathrm{LOH}$ show specific correlation with low $\mathrm{T}$ levels and which are the most specific laboratory parameters to diagnose $\mathrm{LOH}$. The main problem is that many men with high $\mathrm{LOH}$ symptom score have normal circulating $\mathrm{T}$, and many men with low circulating $\mathrm{T}$ are asymptomatic. Clear hypogonadism needs ART irrespective of the age it is diagnosed, but whether androgen therapy is beneficial in mild hypogonadism with diffuse symptomatology, as is usually observed in ageing men, has not yet been solved. 
The symptoms of $\mathrm{LOH}$ in ageing men are very similar to those documented in the classical hypogonadism of young men. As concerns ageing men, direct demonstration of association of the same symptoms with chemically documented hypogonadism, that is, suppressed circulating $\mathrm{T}$ levels, has not been straightforward. Therefore, there is no conclusive evidence for causality between low $\mathrm{T}$ concentrations and most of the $\mathrm{LOH}$ symptoms. There is no identifiable inflection point in age at which $\mathrm{T}$ levels begin to decline more abruptly or rapidly, and there are no generally accepted age-adjusted reference ranges for serum T. According to the present recommendation regarding men eligible for $\mathrm{T}$ substitution therapy, the symptoms of $\mathrm{T}$ deficiency become manifest when total $\mathrm{T}$ is between 12 and $8 \mathrm{nmol} / \mathrm{l}$, and a total $\mathrm{T}$ concentration of $\leq 8 \mathrm{nmol} / \mathrm{l}$ is, as such, an indication for substitution therapy [1]. The question of pathognomonic symptoms may be simpler than expected. Of the wide array of the allegedly LOH-related symptoms, only the sexual symptoms (that is decreased potency, libido and strength of morning erections) show significant association with suppressed T levels [9]; these symptoms also increase most clearly with increasing age [10].

All classical effects of $\mathrm{T}$ are mediated by the androgen receptor. Besides this, the full effect of endogenous $\mathrm{T}$ also includes effects mediated through its metabolites, on one hand by oestrogens and on the other by $5 \alpha$-dihydrotestosterone, a stronger androgenic metabolite of T. Unlike endogenous $\mathrm{T}$, some preparations available for ART do not possess this capability to be metabolized to either oestrogens or $5 \alpha$-dihydrotestosterone. Some of the previously used androgen preparations have been associated with unfavorable side effects. For example, the 17-substituted steroids, but not natural $\mathrm{T}$, have been reported to associate with increases in liver enzymes, cholestasis, peliosis of the liver and also liver tumors.

The availability of preparations suitable for ART varies between countries. Such regimens include dermal preparations (gels and patches), intramuscular injections, subcutaneous pellets and buccal tablets. It is possible with all of them to achieve the target concentration of serum $\mathrm{T}$, which should be in the middle of the reference range of young adult men, that is about $15-20 \mathrm{nmol} / \mathrm{l}$. The disadvantage of oral preparations is their short duration of action due to first-pass metabolism in the liver. Conversely, the long duration of action of injectables may pose a risk that the treatment cannot be rapidly discontinued if serious adverse effects occur. Different formulations and routes of administration have selective benefits, but none is clearly superior to the others.

Testosterone and Ageing

\section{Metabolic Syndrome, Obesity, Lipids and Diabetes}

Metabolic syndrome is defined as a cluster of metabolic disorders that increase the risk of diabetes mellitus and cardiovascular disease, as defined in more detail by WHO, NCEPIII and IDF [11]. The phenotypic signs of metabolic syndrome include central obesity, hypertension, disorders of glucose metabolism and adverse lipid profile including low high-density lipoprotein (HDL)cholesterol and high triglyceride, as well as low-density lipoprotein-cholesterol levels. Although the prevalence of metabolic syndrome increases with age in both sexes, it has higher prevalence in men. Endogenous T is independently associated with a reduced risk of the metabolic syndrome in nonobese ageing men, and low $\mathrm{T}$ predicts the emergence of metabolic syndrome and type 2 diabetes in middle-aged men [12]. Components of metabolic syndrome and type 2 diabetes contribute to the development of atherosclerosis. Due to this overlap, the clinical observations related to metabolic syndrome, diabetes and coronary artery disease are discussed partly collectively in this review.

Obesity is associated with decreased levels of $\mathrm{T}$ in men [4]. This is partly explained by increased conversion of $\mathrm{T}$ to oestrogens by aromatase expressed in the adipose tissue. Of obese men (body mass index $>30$ ), $20-64 \%$ have $\mathrm{T}$ levels in the hypogonadal range, which association mostly reflects the influence of visceral obesity $[4,12]$. T replacement therapy, on the other hand, decreases the waist-hip ratio and weight [13] and therefore seems to counteract some components of the phenotype of metabolic syndrome.

In clinical studies, endogenous $\mathrm{T}$ is associated with better lipid profile in the form of lower total cholesterol and triglycerides as well as higher HDL-cholesterol [14]. $\mathrm{T}$ administration in physiological doses to men has been found to reduce concentrations of total cholesterol, but mainly without other significant changes in lipid profile. However, in men with higher baseline levels of T, ART decreased the HDL-cholesterol levels. Supraphysiological levels of $\mathrm{T}$ in the form of androgenic-anabolic steroids cause changes towards adverse lipid profile [15].

Diabetes is one of the greatest risk factors for developing cardiovascular diseases, and approximately $65 \%$ of diabetics die of cardiovascular complications of their disease [16]. Epidemiological studies demonstrate a clear association between $\mathrm{T}$ and glucose metabolism, linking $\mathrm{T}$ inversely to diabetes and insulin resistance. Low endogenous $\mathrm{T}$ can predict the emergence of diabetes in middleaged men [17]. Of men with type 2 diabetes or metabolic 
syndrome, up to one third have such low T levels that they might qualify for ART [11]. Insulin resistance in ageing men is associated with decreased secretion of $\mathrm{T}$, suggesting possible causality with a reduction in the number of T-producing Leydig cells in the testes. Supporting the relationship between $\mathrm{T}$ and diabetes, $\mathrm{T}$ replacement therapy in non-diabetic men improved their glucose tolerance [12]. The improved glucose metabolism is argued to be secondary to $\mathrm{T}$, since this effect is stronger in patients with lower baseline T levels, and induction of supraphysiological levels of T resulted in impaired glucose metabolism. However, cessation of T therapy decreased insulin sensitivity without changing the body composition [18]. Therefore, it has been suggested that the effect is also mediated through other pathways activated by $\mathrm{T}$.

In conclusion, the cohorts in the studies on association of $\mathrm{T}$ and metabolic syndrome, obesity and glucose disturbances have been small and the findings reported have been variable. It is too early to recommend $\mathrm{T}$ for adjuvant treatment in diabetes, although this interesting concept deserves to be more thoroughly studied.

\section{Cardiovascular Disease}

The highest mortality rates in the Western world are due to atherosclerosis, a progressive disease of the arterial system with onset in childhood or early adulthood. In the past decades, $T$ has been assumed to be atherogenic, since a shift towards an adverse lipid profile is observed in pubertal boys, whereby a decrease in HDLcholesterol is associated with increasing $\mathrm{T}$ levels [19]. Androgenic-anabolic steroids are also associated with dose-dependent impairment of the lipid profile (especially low HDL-cholesterol), activation of the coagulation cascade, haemostasis as well as damaged endothelial and cardiac function [20]. Because of insufficient direct research data on $\mathrm{T}$ and coronary artery disease, several studies have concentrated on common risk factors of coronary artery disease and $\mathrm{T}$ to clarify the possible association.

Low $\mathrm{T}$ levels are associated with several surrogate markers of atherosclerosis and coronary artery disease. Endogenous $\mathrm{T}$ and arterial calcification, a marker of the atherosclerotic process, are inversely associated. Similarly, atherosclerosis in terms of increased carotid artery intima-media thickness is a marker of advancing atherosclerosis and seems to predict cardiovascular disease, stroke and mortality [21]. Increased carotid intima-media thickness has been associated with lower levels of $\mathrm{T}$ in ageing men. Low androgen levels are also indicative of increased mortality due to cardiovascular diseases of all causes.

Inflammation plays an important role in the formation, and later on in the rupture of atherosclerotic lesions in arterial walls. In the latter the haemostatic characteristics are equally essential. Endogenous T has been associated with a decrement of the inflammatory state by reducing interleukin (IL)-6, hCRP, tumor necrosis factor$\alpha$, and IL-1B [22], and vice versa, as well as low levels of T have been associated with inflammatory cytokines such as IL-2, IL-4 and complement C. Promoting thrombosis, plasminogen activator inhibitor-1, fibrinogen, $\alpha 2$-antiplasmin and factor VII are negatively associated with endogenous $\mathrm{T}$ [11]. Furthermore, promoting fibrinolysis, $\mathrm{T}$ is directly associated with tissue plasminogen activator. In the case of inflammation, T may be protective against atherosclerosis through beneficial immunomodulation, and influences on plaque development and stability.

The main relieving effect of $\mathrm{T}$ on angina pectoris is thought to be vasodilatation, and a rapid non-genomic vasodilatory action of $\mathrm{T}$ has been documented independent of the classical nuclear androgen receptor activation $[23,24]$.

On the other hand, the classical genomic vasodilatation is also involved, since $\mathrm{T}$ is suggested to release nitric oxide. However, this, as well as other atheroprotective properties of $\mathrm{T}$, have been argued to be mediated through its conversion to oestrogens [25]. In men with stabile coronary artery disease, transdermal $\mathrm{T}$ in addition to normal coronary artery disease medication seems to improve the angina threshold in treadmill exercise at 4 weeks and 3 months after start of the treatment [26]. Intracoronary infusion of $\mathrm{T}$ induces artery dilatation in men with coronary artery disease [27]. However, no association has been observed between $\mathrm{T}$ and coronary atherosclerosis in angiographic studies.

In summary, the higher prevalence of cardiovascular disease in men suggests involvement of androgens, prompting caution in prescribing $\mathrm{T}$ replacement therapy for ageing men, especially if they have symptomatic coronary artery disease. However, numerous studies, albeit relatively small in size, on the association of androgens and coronary artery disease have found no adverse effect of $\mathrm{T}$ on this disease. Neither have the studies shown significant beneficial effects of androgen treatment in primary or secondary prevention. 


\section{Heart Failure}

Severe congestive heart failure is frequently listed in the pharmacopeia as a contraindication to $\mathrm{T}$ therapy. Heart failure is associated with increased secretion of inflammatory cytokines and increased inflammatory response, and it induces metabolic and endocrinological alterations, such as changes in glucose metabolism as well as levels of growth hormone and $\mathrm{T}$ [28]. In patients with heart failure, over $40 \%$ are diagnosed with disturbance of glucose metabolism not explained by obesity or fat distribution [28]. Approximately 25\% of men with chronic heart failure have $\mathrm{T}$ levels below the normal range, and low levels of $\mathrm{T}$ seem to relate to the progression of heart failure [29]. ART of men with heart failure improves their cardiac function and decreases the levels of the heart failure indicator, brain natriuretic peptide. T replacement therapy decreases the symptoms of heart failure, as measured by the New York Heart Association functional class, and it improves the exercise capacity [30]. In a recent study, $\mathrm{T}$ therapy combined with the conventional treatment of heart failure improved muscle strength, exercise capacity, insulin sensitivity and baroreflex sensitivity [31]. In this study, T therapy did not improve myocardial function, suggesting that the effects are not mediated through improvement in cardiac function but merely through other associated mechanisms not entirely known.

\section{Effect of T Treatment on Bone and Osteoporosis}

Although osteoporosis is usually considered a disease of older women, it also affects ageing men. The higher peak bone mass protects men from osteoporosis, but they also start to lose bone mass in early adulthood and with increasing rate in old age. The prevalence of osteoporosis in men has apparently been underestimated. The gap between sexes narrows with age, and it is remarkable that hip fractures in men are associated with almost 2-fold greater mortality than in women [32]. Numerous studies show direct correlation of circulating $\mathrm{T}$ and oestradiol (E2) levels and bone mineral density (BMD) in men, and consequently hypogonadism is found in up to $20 \%$ in men with symptomatic vertebral fractures and in 50\% with hip fractures [33]. Many studies emphasize the role of $\mathrm{E} 2$ in determining BMD also in men, but because $\mathrm{E} 2$ is a metabolite of $\mathrm{T}$, the levels of these 2 sex steroids apparently correlate. Optimal levels of both sex steroids are needed for the maintenance of BMD in men, and with ageing-related decline of $\mathrm{T}$ also a relative oestrogen deficiency may occur with its detrimental effect on the bone. The importance of aromatisable androgens for bone health is demonstrated by treatment trials where nonaromatisable androgens are inferior in comparison to exogenous or human chorionic gonadotropin-stimulated endogenous $\mathrm{T}$ in improving BMD [34].

There is thus ample background information for the hypothesis that $\mathrm{T}$ replacement therapy could be beneficial for the bone, and a large number of studies have shown positive effects. There are two meta-analyses on the benefits of androgen treatment on bone in ageing men $[35,36]$. One analysis included 5 trials with a total of 264 subjects and the other 8 trials with 365 subjects. Both analyses documented inconsistent treatment effects, most probably due to differences in effects of the different androgen preparations used. T treatment increased BMD at the lumbar spine by a significant $3.7 \%$ (confidence interval 1.0-6.4\%) compared to placebo after a minimum of 12-36 months of treatment, but no significant effect was found at the femoral neck. Some evidence for partial response was provided by reduced levels of bone resorption markers.

A seminal study on T treatment of ageing men [37], carried out in randomised placebo-controlled fashion, for 36 months in 108 men, with mean T levels of 12.8 $\mathrm{nmol} / \mathrm{l}$, found no treatment effect in the whole study group. However, a linear inverse relationship was found between pretreatment $\mathrm{T}$ and increase in BMD, the effect being significant in men with the lowest pretreatment levels of $\mathrm{T}$. This allowed the conclusion that $\mathrm{T}$ treatment is effective only in men with hypogonadal $\mathrm{T}$ levels and it does not improve BMD of eugonadal men. The BMD response was linear during the 36-month treatment period, suggesting the need of long treatment to achieve clinically significant improvement. In agreement with the latter study, a recent trial with oral $\mathrm{T}$ undecanoate supplementation for asymptomatic men with $\mathrm{T}<13.7 \mathrm{nmol} / \mathrm{l}$ for 6 months did not improve BMD [38]. Hence, the current information indicates that ART for the prevention or treatment of osteoporosis is effective only in hypogonadal men and it has to be of sufficient length (years) to be beneficial.

The implications from the results so far available support the use of $\mathrm{T}$ in enhancing bone health in hypogonadal men, but whether the treatment choice should be adding $\mathrm{T}$ to the alternative treatments with calcium, vitamin $\mathrm{D}$ and bisphosphonates remains unclear. A rather long treatment time, maybe over 2 years, is needed for clear clinically meaningful effects, and documented im- 
provement is achieved only in the spine but not in the hip. Most importantly, no data exist on beneficial association of the improved BMD with lowered fracture rates or quality of life. At the moment, large randomized trials with long duration ( $>3$ years) are needed, and the benefits of $\mathrm{T}$ in comparison to the established therapies should be assessed.

\section{Effect of T Treatment on Muscle Strength and Frailty}

Ageing-associated sarcopenia is an important public health issue that contributes importantly to the frailty of the elderly, including increasing frequency of falls and fractures, dependence and finally deaths. Anabolic interventions to prevent ageing-related sarcopenia are therefore desirable. Besides growth hormone and IGF-1, T offers a possible pharmacological means to achieve this goal. The effects of $\mathrm{T}$ on muscle mass are well documented in young men, not the least through the anecdotal evidence from anabolic steroid abuse by athletes. A fair amount of information exists that also in older men androgens have significant effects on suppressing fat mass and increasing lean body mass as well as muscle size and strength $[39,40]$.

Unlike some other effects of androgens reviewed here, only documented in hypogonadal men, the dose response of muscle strength and size gain to androgen treatment seems to be linear across a wide range of $\mathrm{T}$ doses from hypogonadal to supraphysiological levels. This information is well known by bodybuilders and athletes aiming at maximising muscle size and strength. It is therefore not surprising that similar effects of $\mathrm{T}$ can be demonstrated in ageing men. Storer et al. [41] studied the effect of graded doses of $\mathrm{T}$ in healthy older men whose endogenous $\mathrm{T}$ production was blocked by gonadotropin-releasing hormone agonist treatment. The treatment levels of $\mathrm{T}$ ranged 10 -fold from hypogonadal to supraphysiological. A linear response to $\mathrm{T}$ was observed in skeletal muscle mass and leg power as well as strength, but no consistent effects were found on performance-based measures such as muscle fatigability, walking, climbing stairs or rising from chair. The poor correlation between muscle strength and performance may have been due to the lack of physical symptoms in this study group of healthy men. In the same way, in older men with low or low-normal T levels, $\mathrm{T}$ therapy only consistently increases lean body mass without effects on muscle performance. Most studies agree upon the effect of $\mathrm{T}$ on muscle mass and strength, but the effects on performance-based measures of physi- cal function are variable. Conspicuously, the meta-analysis of Ottenbacher et al. [42] reported an inverse relation between the effect size and quality of study, including the possibility of reporting bias. Hence, in the absence of large well-controlled studies the information from small poorly controlled or uncontrolled studies may give a biased view about the benefits of $\mathrm{T}$ treatment.

Reasons for the discrepancy between T effects on muscle strength and physical performance are not clear. It is possible that long $\mathrm{T}$ treatment is needed for neuromuscular and neurovascular adaptations of the newly accrued muscle fibres into a functional unit. It has also been suggested that translation of the increased muscle strength into physical function is not straightforward, but needs cognitive, behavioural and functional training. More information is needed about the potential use of androgens in improving muscular performance of ageing men. Such studies should include men with clear limitations in muscle performance, be sufficiently long and include functional and behavioural training as an adjunct to the expected gain of muscle mass.

\section{Effect of T Treatment on Sexual Function}

The majority of older men remain sexually active, but their proportion decreases with age, from $84 \%$ between 57 and 64 years to $49 \%$ between 70 and 75 years [43]. Impaired sexual function, often due to erectile dysfunction (ED), with a prevalence of up to $70 \%$ in men over 70 years of age, is a major determinant of worsened quality of life in older men. Its aetiology is multifactorial, including emotional, vascular, neurological and pharmacological components. Numerous studies with varying size, duration and quality have been carried out on ART of impaired sexual function of ageing men. Although the decline of androgen levels and increase of erectile dysfunction parallel upon ageing, a convincing causal link between ED and low T has not been established. However, the recent data from the European Male Ageing Study indicate that sexual symptoms (decreased potency, libido and morning erections) are the only ones of the large array of 'andropausal' symptoms with significant inverse correlation with circulating T levels [9]. Although androgen treatment of ED is a common practice, it still has to be considered empirical, based on personal experience and uncontrolled evidence.

There are ample experimental data on beneficial effects of $\mathrm{T}$ on various aspects of penile function. Animal experiments have shown vasodilatory effects of $\mathrm{T}$ treat- 
ment and that $\mathrm{T}$ regulates the synthesis of nitric oxide and expression of phosphodiesterase type 5 (PDE5) in the penis. Importantly, $\mathrm{T}$ affects several aspects of the sexual function of healthy men, and androgen therapy of classical hypogonadism in young men improves all aspects of their sexual function. The duration and quality of nocturnal penile tumescence is considered to be clearly under $\mathrm{T}$ regulation, rather than erections evoked by visual erotic stimuli. In young men, $\mathrm{T}$ increases sexual interest, motivation and arousability, but in older men the relationship is complicated by simultaneous documented or putative alterations in the hypothalamic-pituitary feedback, increased sex hormone-binding globulin levels and androgen receptor sensitivity. $\mathrm{T}$ replacement increases the frequency of sexual thoughts and feelings, but the effect is greater in younger hypogonadal men than in ageing men. Apparently only clearly decreased androgen levels worsen these aspects of male sexual function. Altogether, the relationship of $\mathrm{T}$ levels with the different components of libido is complex. Most studies report that all aspects of erectile function improve by $\mathrm{T}$ treatment in hypogonadal men, but the effect disappears if the basal level of $\mathrm{T}$ is $>12 \mathrm{nmol} / \mathrm{l}$. The response to $\mathrm{T}$ was greater in men with vasculogenic than psychogenic ED.

Two recent meta-analyses on effects of $\mathrm{T}$ treatment on sexual function in men have been published. Both analyses included 17 randomised placebo-controlled studies, 12 of them the same, encompassing 656 and 862 subjects. The main conclusions of the study by Isidori et al. [44] were as follows. (1) In men with basal total $\mathrm{T}<12 \mathrm{nmol} / \mathrm{l}$, there was a moderate improvement in the number of nocturnal erections, sexual thoughts and motivation, number of successful intercourses, scores of erectile function and overall sexual satisfaction. (2) No effects were found in eugonadal men, and the effect on erectile function, but not on libido, was inversely related to the basal $\mathrm{T} \mathrm{lev-}$ el. (3) The significant effects tended to decrease with time. The conclusions in the meta-analysis by Bolona et al. [45] in men with low T levels were as follows. (1) A moderate non-significant and inconsistent effect was found on satisfaction with erectile function. (2) A larger effect was found on libido. (3) There was no effect on sexual satisfaction. The effects were clearly weaker in men with low-normal to normal $\mathrm{T}$. Both studies recognized the possibility of publication bias, with negative findings remaining unpublished. In conclusion, the meta-analyses showed that only men with documented hypogonadism might benefit from $T$ treatment. The effect on ED was marginal and probably greater on libido. The meta-analyses highlighted the need of large-scale, long-term ran- domised studies to establish the real benefits of $\mathrm{T}$ treatment for sexual function in middle-aged and elderly men.

After the meta-analyses, a number of small and often uncontrolled studies have been reported on benefits of $\mathrm{T}$ therapy, but their messages remain largely inconclusive. As an interesting detail, several studies have shown that T treatment may improve the response of men unresponsive to ED treatment with PDE5 inhibitors. There is experimental evidence that PDE5 inhibitors do not function effectively in hypoandrogenic conditions [46].

Finally, two large ( $\mathrm{n}=237$ and 322) double-blind placebo-controlled trials have been recently conducted on effects of orally administered $\mathrm{T}$ undecanoate, amongst other effects, on sexual function of ageing men [47, 48]. The inclusion criteria for basal $\mathrm{T}$ were rather high in both studies (total $\mathrm{T}<13.7 \mathrm{nmol} / \mathrm{l}$ and calculated free $\mathrm{T}<0.26$ $\mathrm{nmol} / \mathrm{l}$ ). One dose of $80 \mathrm{mg} \mathrm{T}$ undecanoate/day (for 6 months) was used in the former and 3 doses on 80, 160 and $240 \mathrm{mg} / \mathrm{day}$ (for 12 months) in the latter study. The effects of treatment on sexual function were completely negative in the former study. In the latter study, the middle, but not the low or high dose of $\mathrm{T}$ undecanoate, brought about a modest improvement in the sexual symptoms score. It is possible that the dose of $\mathrm{T}$ was insufficient and the patient group was not sufficiently hypogonadal to benefit from the treatments. Hence, we still have to wait for properly designed conclusive studies to find out whether T is useful in the treatment of ED of ageing men. The pharmaceutical industry is understandably reluctant to launce such studies. The empirical $T$ treatment is common even in the absence of evidence-based proof, and on the basis of the current fragmentary information, a study providing conclusive scientific evidence for the issue is more likely to yield negative than positive results.

\section{Effect on Mood, Energy and Cognition}

Sex hormones are generally thought to influence mood and cognition. Decreased $\mathrm{T}$ levels in ageing are associated with depression, poorer cognitive functions and even Alzheimer's disease. In experimental studies, T seems to possess neuroprotective effects. In T replacement studies, a beneficial effect has been observed on mood in men with clearly subnormal levels of $\mathrm{T}$ [49]. The effect was absent in men with low normal levels of T. Overall, beneficial effects of $T$ treatment on mental status of men have been observed, but so far T therapy can at most be considered to relieve symptoms of $\mathrm{LOH}$. 


\section{Side-Effects of T Therapy}

The use of exogenous $\mathrm{T}$ is in some cases associated with adverse behaviour, such as excessive libido and aggression. Gynaecomastia has also been described in men using exogenous androgens. This seems to be caused by the aromatization of T to E2 in peripheral tissue. Exogenous $\mathrm{T}$ also causes suppression of spermatogenesis by enhancing the negative feedback on gonadotropin secretion.

T stimulates erythopoiesis by increasing the reticulocyte count and haemoglobin levels, but the effect is apparently not mediated by renal stimulation on erythropoietin production. At puberty, $\mathrm{T}$ increases haemoglobin levels of boys by $5-20 \%$. T deficiency, on the other hand, is estimated to decrease haemoglobin by the same amount. Due to its documented effect on erythropoiesis, T treatment is not recommended for men with haematocrit $>52 \%$. Hence, haematocrit should be controlled at the beginning of the treatment and after 3-4 and 12 months of treatment. The risk for too high haematocrit is stronger with injectable preparations and it increases with age.

$\mathrm{T}$ replacement therapy has been associated with benign and malignant hepatic tumours, intrahepatic cholestasis and hepatotoxicity and liver failure. The majority of hepatotoxicity is associated with oral preparations, excluding $\mathrm{T}$ undecanoate. These older anabolic steroids with $17 \alpha$-alkylated structure have been removed from the clinical use in most countries. Adverse hepatic effects are not observed with transdermal or intramuscular preparations because they avoid the first-pass metabolism in liver.

Development or worsening of sleep apnoea may be associated with T treatment [50,51], and therefore it is considered a contraindication for $\mathrm{T}$ replacement therapy. It seems that $\mathrm{T}$ contributes to sleep apnoea through the central nervous system [50], but it may also have a direct effect on the larynx, which is an androgen-responsive organ. Hypoxia in connection with sleep apnoea may explain partly the $\mathrm{T}$ treatment-associated increase in haematocrit.

Prostate cancer is one of the commonest cancers in ageing men, with high incidence and prevalence especially in western countries. Similarly among ageing men, prostate hyperplasia is a common condition in men with normal T levels. However, in the studies conducted, no significant adverse effects have been observed with $\mathrm{T}$ replacement therapy [52]. Although the growth of existing prostate cancer is promoted by androgens, several recent studies have shown that $T$ replacement therapy in ageing men does not raise the incidence of prostate cancer [53].
In fact, men with treated prostate cancer have been successfully treated with $\mathrm{T}$ replacement therapy, albeit the studies have been small and therefore inconclusive to provide final answer. In the follow-up, prostate-specific antigen levels have been stabile and the incidence of prostate cancer has been similar with the general population [54]. However, more long-term information is still needed on the potential risks of prostatic diseases and ART. Careful monitoring of prostatic health is a wise precaution in all ageing men receiving $\mathrm{T}$ treatment, and in particular in those with higher risk, such as African descent, strong family history and higher prostate-specific antigen levels.

\section{Conclusions and Future Perspectives}

Data on the diagnostic criteria, and hence the prevalence, of $\mathrm{LOH}$ are still conflicting and remain a matter of sophisticated debate. The estimated prevalence of $\mathrm{LOH}$ ranges significantly from 0.5 up to $50 \%$ towards older men. The hormonal mechanisms and aetiology responsible for the $\mathrm{T}$ decrement in ageing seem complex. The activity to diagnose and treat $\mathrm{LOH}$ patients has increased, and in the US, the annual increase in T prescriptions has reached 29\% in the 21st century. The European statistics indicate a more stabile and conservative approach to the condition. Despite several observed benefits, T replacement therapy of middle-aged and older men is not totally risk-free. There are several promising associations of health benefits with raised $\mathrm{T}$ levels within the subnormal range of this hormone, but to date there is practically no evidence to support treatment of men with normal T levels. When the T levels are clearly decreased, often in conjunction with obesity and systemic disease, such as coronary artery disease and diabetes, it is conceivable that $\mathrm{T}$ replacement could provide a useful adjuvant therapy. However, it still seems more conceivable that weight reduction and good balance of co-morbid diseases, rather than a lifelong, expensive and not totally risk-free $\mathrm{T}$ therapy, is the most logical primary treatment of low $\mathrm{T}$ in the majority of ageing men. With respect to $\mathrm{T}$ replacement therapy, no evidence-based information is available yet on such important questions as the duration of treatment, long-term effects on testicular function and long-term benefits and risks. 


\section{References}

$>1$ Nieschlag E, Swerdloff R, Behre HM, Gooren 11 Stanworth RD, Jones TH: Testosterone for LJ, Kaufman JM, Legros JJ, Lunenfeld B, Morley JE, Schulman C, Wang C, Weidner $\mathrm{W}, \mathrm{Wu}$ FC: Investigation, treatment and monitoring of late-onset hypogonadism in males. Aging Male 2005;8:56-58.

2 Werner A: The male climacteric. JAMA 1939;112:1441-1443.

-3 Lamberts SW, van den Beld AW, van der Lely AJ: The endocrinology of aging. Science 1997;278:419-424.

$>4$ Wu FC, Tajar A, Pye SR, Silman AJ, Finn JD, O’Neill TW, Bartfai G, Casanueva F, Forti G, Giwercman A, Huhtaniemi IT, Kula K, Punab M, Boonen S, Vanderschueren D: Hypothalamic-pituitary-testicular axis disruptions in older men are differentially linked to age and modifiable risk factors: the European male aging study. J Clin Endocrinol Metab 2008;93:2737-2745.

$\checkmark 5$ Feldman HA, Longcope C, Derby CA, Johannes $\mathrm{CB}$, Araujo AB, Coviello AD, Bremner WJ, McKinlay JB: Age trends in the level of serum testosterone and other hormones in middle-aged men: longitudinal results from the massachusetts male aging study. J Clin Endocrinol Metab 2002;87:589-598.

-6 Isidori AM, Lenzi A: Risk factors for androgen decline in older males: lifestyle, chronic diseases and drugs. J Endocrinol Invest 2005; 28:14-22.

7 Harman SM, Metter EJ, Tobin JD, Pearson J, Blackman MR: Longitudinal effects of aging on serum total and free testosterone levels in healthy men. Baltimore longitudinal study of aging. J Clin Endocrinol Metab 2001;86: 724-731.

$>8$ Tajar A, Forti G, O’Neill TW, Lee DM, Silman AJ, Finn JD, Bartfai G, Boonen S, Casanueva FF, Giwercman A, Han TS, Kula K, Labrie F, Lean ME, Pendleton N, Punab M, Vanderschueren D, Huhtaniemi IT, Wu FC, the EMAS Group: Characteristics of secondary, primary, and compensated hypogonadism in aging men: evidence from the European male ageing study. J Clin Endocrinol Metab 2010;98:1810-1818.

$>9$ Wu F, Tajar A, Beynon M, Pye S, Silman A, Finn J, O’Neill T, Bartfai G, Casanueva F, Forti G, Giwercman A, Han T, Kula K, Lean $\mathrm{M}$, Pendleton $\mathrm{N}$, Punab $\mathrm{M}$, Boonen $\mathrm{S}$, Vanderschueren D, Labrie F, Huhtaniemi I, the EMAS Group: Identification of late-onset hypogonadism in middle-aged and elderly men: Results from the European male aging study. N Engl J Med 2010;363:123-135.

-10 Mäkinen JI, Perheentupa A, Raitakari OT, Koskenvuo M, Pöllänen $\mathrm{P}$, Mäkinen J, Huhtaniemi I: Sexual symptoms in aging men indicate poor life satisfaction and increased health service consumption. Urology 2007;70:1194-1199. the aging male; current evidence and recommended practice. Clin Interv Aging 2008;3: 25-44.

12 Bassil N, Alkaade S, Morley JE: The benefits and risks of testosterone replacement therapy: a review. Ther Clin Risk Manag 2009;5: 427-448.

13 Boyanov MA, Boneva Z, Christov VG: Testosterone supplementation in men with type 2 diabetes, visceral obesity and partial androgen deficiency. Aging Male 2003;6:1-7.

14 Mäkinen JI, Perheentupa A, Irjala K, Pöllänen P, Mäkinen J, Huhtaniemi I, Raitakari OT: Endogenous testosterone and serum lipids in middle-aged men. Atherosclerosis 2008;197:688-693.

15 Ebenbichler CF, Sturm W, Ganzer H, Bodner J, Mangweth B, Ritsch A, Sandhofer A, Lechleitner M, Foger B, Patsch JR: Flow-mediated, endothelium-dependent vasodilatation is impaired in male body builders taking anabolic-androgenic steroids. Atherosclerosis 2001;158:483-490.

16 Selvin E, Feinleib M, Zhang L, Rohrmann S, Rifai N, Nelson WG, Dobs A, Basaria S, Golden SH, Platz EA: Androgens and diabetes in men: results from the Third National Health and Nutrition Examination Survey (NHANES III). Diabetes Care 2007;30:234238.

17 Laaksonen DE, Niskanen L, Punnonen K, Nyyssönen K, Tuomainen TP, Valkonen VP, Salonen R, Salonen JT: Testosterone and sex hormone-binding globulin predict the metabolic syndrome and diabetes in middle-aged men. Diabetes Care 2004;27:1036-1041.

18 Yialamas MA, Dwyer AA, Hanley E, Lee H, Pitteloud N, Hayes FJ: Acute sex steroid withdrawal reduces insulin sensitivity in healthy men with idiopathic hypogonadotropic hypogonadism. J Clin Endocrinol Metab 2007;92:4254-4259.

19 Kirkland RT, Keenan BS, Probstfield JL, Patsch W, Lin TL, Clayton GW, Insull W Jr: Decrease in plasma high-density lipoprotein cholesterol levels at puberty in boys with delayed adolescence. Correlation with plasma testosterone levels. JAMA 1987;257:502507.

20 Sullivan ML, Martinez CM, Gennis P, Gallagher EJ: The cardiac toxicity of anabolic steroids. Prog Cardiovasc Dis 1998;41:1-15.

21 Bots ML, Hoes AW, Hofman A, Witteman JC, Grobbee DE: Cross-sectionally assessed carotid intima-media thickness relates to long-term risk of stroke, coronary heart disease and death as estimated by available risk functions. J Intern Med 1999;245:269-276.

22 Maggio M, Basaria S, Ble A, Lauretani F, Bandinelli S, Ceda GP, Valenti G, Ling SM, Ferrucci L: Correlation between testosterone and the inflammatory marker soluble interleukin- 6 receptor in older men. J Clin Endocrinol Metab 2006;91:345-347.
23 Jones RD, Pugh PJ, Hall J, Channer KS, Jones TH: Altered circulating hormone levels, endothelial function and vascular reactivity in the testicular feminised mouse. Eur J Endocrinol 2003; 148:111-120.

24 Yildiz O, Seyrek M: Vasodilating mechanisms of testosterone. Exp Clin Endocrinol Diabetes 2007;115:1-6.

25 Nathan L, Shi W, Dinh H, Mukherjee TK, Wang X, Lusis AJ, Chaudhuri G: Testosterone inhibits early atherogenesis by conversion to estradiol: critical role of aromatase. Proc Natl Acad Sci USA 2001;98:3589-3593.

26 English KM, Steeds RP, Jones TH, Diver MJ, Channer KS: Low-dose transdermal testosterone therapy improves angina threshold in men with chronic stable angina: a randomized, double-blind, placebo-controlled study. Circulation 2000;102:1906-1911.

27 Webb CM, McNeill JG, Hayward CS, de Zeigler D, Collins P: Effects of testosterone on coronary vasomotor regulation in men with coronary heart disease. Circulation 1999; 100:1690-1696.

28 von Haehling S, Doehner W, Anker SD: Nutrition, metabolism, and the complex pathophysiology of cachexia in chronic heart failure. Cardiovasc Res 2007;73:298-309.

29 Malkin CJ, Jones TH, Channer KS: Testosterone in chronic heart failure. Front Horm Res 2009;37:183-196.

30 Malkin CJ, Pugh PJ, West JN, van Beek EJ, Jones TH, Channer KS: Testosterone therapy in men with moderate severity heart failure: a double-blind randomized placebo controlled trial. Eur Heart J 2006;27:57-64.

-31 Caminiti G, Volterrani M, Iellamo F, Marazzi G, Massaro R, Miceli M, Mammi C, Piepoli M, Fini M, Rosano GM: Effect of long-acting testosterone treatment on functional exercise capacity, skeletal muscle performance, insulin resistance, and baroreflex sensitivity in elderly patients with chronic heart failure a double-blind, placebo-controlled, randomized study. J Am Coll Cardiol 2009;54:919-927.

32 Campion JM, Maricic MJ: Osteoporosis in men. Am Fam Physician 2003;67:1521-1526.

33 Tuck SP, Francis RM: Testosterone, bone and osteoporosis. Front Horm Res 2009;37:123132.

34 Meier C, Liu PY, Ly LP, de Winter-Modzelewski J, Jimenez M, Handelsman DJ, Seibel MJ: Recombinant human chorionic gonadotropin but not dihydrotestosterone alone stimulates osteoblastic collagen synthesis in older men with partial age-related androgen deficiency. J Clin Endocrinol Metab 2004;89:3033-3041.

35 Isidori AM, Giannetta E, Greco EA, Gianfrilli D, Bonifacio V, Isidori A, Lenzi A, Fabbri A: Effects of testosterone on body composition, bone metabolism and serum lipid profile in middle-aged men: a meta-analysis. Clin Endocrinol (Oxf) 2005;63:280-293. 
\$3 Tracz MJ, Sideras K, Bolona ER, Haddad RM, Kennedy CC, Uraga MV, Caples SM, Erwin PJ, Montori VM: Testosterone use in men and its effects on bone health. A systematic review and meta-analysis of randomized placebo-controlled trials. J Clin Endocrinol Metab 2006;91:2011-2016.

-37 Snyder PJ, Peachey H, Hannoush P, Berlin JA, Loh L, Holmes JH, Dlewati A, Staley J, Santanna J, Kapoor SC, Attie MF, Haddad JG Jr, Strom BL: Effect of testosterone treatment on bone mineral density in men over 65 years of age. J Clin Endocrinol Metab 1999; 84:1966-1972.

38 Emmelot-Vonk MH, Verhaar HJ, Nakhai Pour HR, Aleman A, Lock TM, Bosch JL, Grobbee DE, van der Schouw YT: Effect of testosterone supplementation on functional mobility, cognition, and other parameters in older men: a randomized controlled trial. JAMA 2008;299:39-52.

-39 Bhasin S, Calof OM, Storer TW, Lee ML, Mazer NA, Jasuja R, Montori VM, Gao W, Dalton JT: Drug insight: testosterone and selective androgen receptor modulators as anabolic therapies for chronic illness and aging. Nat Clin Pract Endocrinol Metab 2006; 2:146-159.

40 Srinivas-Shankar U, Roberts SA, Connolly MJ, O'Connell MD, Adams JE, Oldham JA, Wu FC: Effects of testosterone on muscle strength, physical function, body composition, and quality of life in intermediate-frail and frail elderly men: a randomized, doubleblind, placebo-controlled study. J Clin Endocrinol Metab 2010;95:639-650.

-41 Storer TW, Woodhouse L, Magliano L, Singh AB, Dzekov C, Dzekov J, Bhasin S: Changes in muscle mass, muscle strength, and power but not physical function are related to testosterone dose in healthy older men. J Am Geriatr Soc 2008;56:1991-1999.
42 Ottenbacher KJ, Ottenbacher ME, Ottenbacher AJ, Acha AA, Ostir GV: Androgen treatment and muscle strength in elderly men: a meta-analysis. J Am Geriatr Soc 2006; 54:1666-1673.

43 Lindau ST, Schumm LP, Laumann EO, Levinson W, O’Muircheartaigh CA, Waite LJ: A study of sexuality and health among older adults in the United States. N Engl J Med 2007;357:762-774.

44 Isidori AM, Giannetta E, Gianfrilli D, Greco EA, Bonifacio V, Aversa A, Isidori A, Fabbri A, Lenzi A: Effects of testosterone on sexual function in men: results of a meta-analysis. Clin Endocrinol (Oxf) 2005;63:381-394.

45 Bolona ER, Uraga MV, Haddad RM, Tracz MJ, Sideras K, Kennedy CC, Caples SM, Erwin PJ, Montori VM: Testosterone use in men with sexual dysfunction: a systematic review and meta-analysis of randomized placebo-controlled trials. Mayo Clin Proc 2007;82:20-28.

46 Morelli A, Filippi S, Mancina R, Luconi M, Vignozzi L, Marini M, Orlando C, Vannelli GB, Aversa A, Natali A, Forti G, Giorgi M, Jannini EA, Ledda F, Maggi M: Androgens regulate phosphodiesterase type 5 expression and functional activity in corpora cavernosa. Endocrinology 2004;145:2253-2263.

47 Emmelot-Vonk MH, Verhaar HJ, NakhaiPour HR, Grobbee DE, van der Schouw YT: Effect of testosterone supplementation on sexual functioning in aging men: a 6-month randomized controlled trial. Int J Impot Res 2009;21:129-138.
48 Legros JJ, Meuleman EJ, Elbers JM, Geurts TB, Kaspers MJ, Bouloux PM: Oral testosterone replacement in symptomatic late-onset hypogonadism: effects on rating scales and general safety in a randomized, placebocontrolled study. Eur J Endocrinol 2009;160: 821-831.

49 Wang C, Swerdloff RS, Iranmanesh A, Dobs A, Snyder PJ, Cunningham G, Matsumoto AM, Weber T, Berman N: Transdermal testosterone gel improves sexual function, mood, muscle strength, and body composition parameters in hypogonadal men. J Clin Endocrinol Metab 2000;85:2839-2853.

50 Matsumoto AM, Sandblom RE, Schoene RB, Lee KA, Giblin EC, Pierson DJ, Bremner WJ: Testosterone replacement in hypogonadal men: effects on obstructive sleep apnoea, respiratory drives, and sleep. Clin Endocrinol (Oxf) 1985;22:713-721.

51 Liu PY, Yee B, Wishart SM, Jimenez M, Jung DG, Grunstein RR, Handelsman DJ: The short-term effects of high-dose testosterone on sleep, breathing, and function in older men. J Clin Endocrinol Metab 2003;88: 3605-3613.

52 Holyoak JD, Crawford ED, Meacham RB: Testosterone and the prostate: Implications for the treatment of hypogonadal men. Curr Urol Rep 2008;9:500-505.

53 Holmang S, Marin P, Lindstedt G, Hedelin $\mathrm{H}$ : Effect of long-term oral testosterone undecanoate treatment on prostate volume and serum prostate-specific antigen concentration in eugonadal middle-aged men. Prostate 1993;23:99-106.

-54 Coward R, Simhan J, Carson Cr: Prostatespecific antigen changes and prostate cancer in hypogonadal men treated with testosterone replacement therapy. BJU Int 2009;103: 1179-1183. 